\title{
Notes on the vocalizations of Dusky Bush-tanager (Chlorospingus semifuscus)
}

\section{Peter Boesman}

In the following we briefly analyze and compare voice of the two races of Dusky Bushtanager (Chlorospingus semifuscus). We also try to quantify the extent of any vocal differences using the criteria proposed by Tobias et al. (2010), as a support for taxonomic review. We have made use of sound recordings available on-line from Xeno Canto (XC), and recordings of song of northern race livingstoni were kindly provided by Johnnier ArangoBermúdez.

Song of both races is a repeated single high-pitched note. A comparison, illustrated with sonograms:

\section{livingstoni}

* song

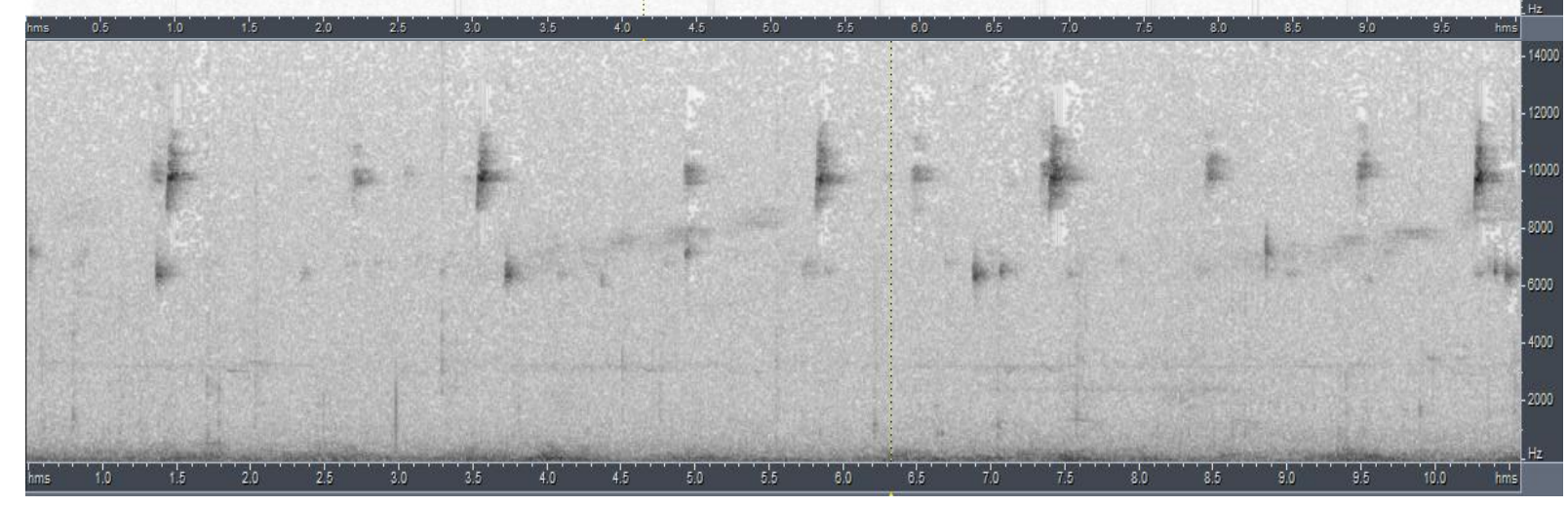

* calls

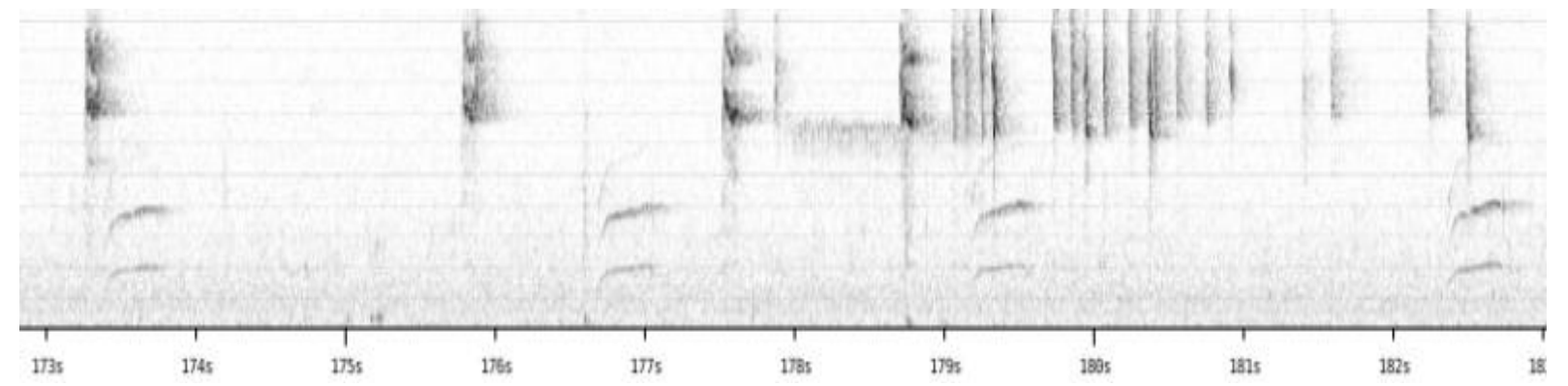


HANDBOOK OF THE

BIRDSPITE WORLD ORNTHOLOGICAL NOTES

nominate

* song
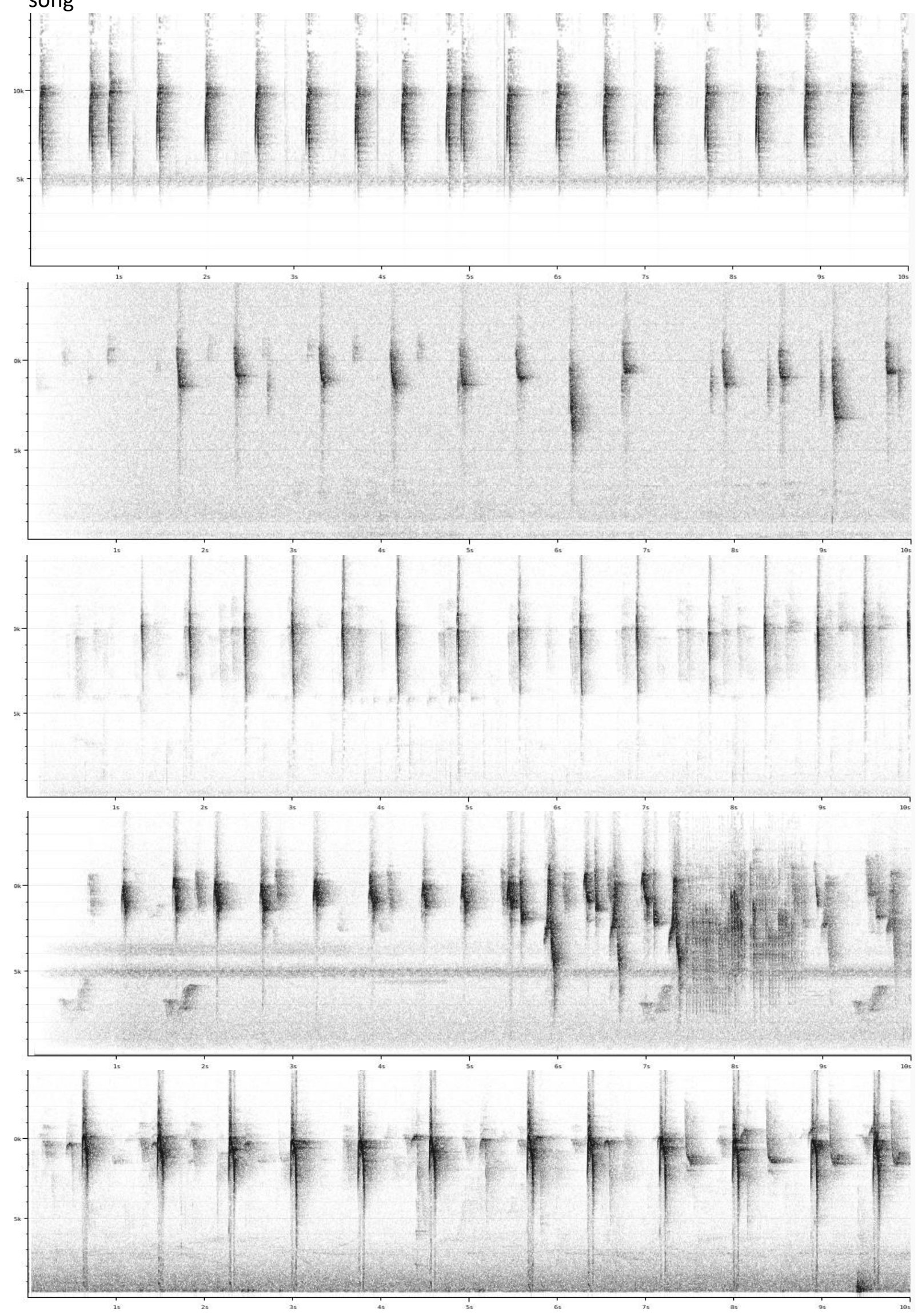

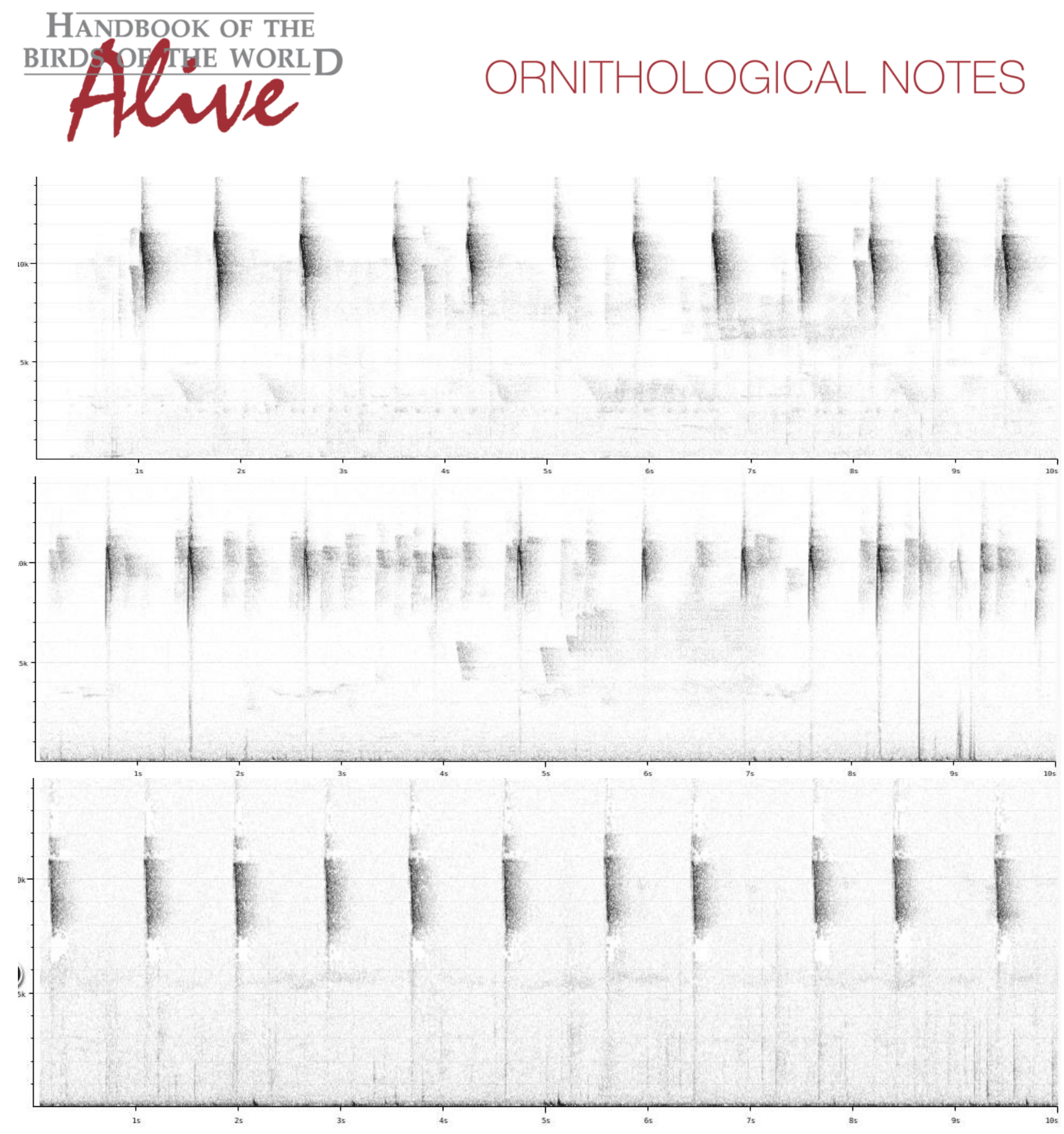

Song of both races is a repeated single high-pitched note, with similar pace. Given this very simple song, we should thus focus on this single note.

In nominate this single note typically is an 'upside down sharp $\mathrm{V}^{\text {', }}$ with usually main emphasis on the downslurred part. Max. frequency typically $10-11 \mathrm{kHz}$.

Note shape of livingstoni is apparently quite different, rather an irregular upslurred note (which has not been found amidst the more numerous recordings of nominate).

See sonograms on next page for a more detailed picture.

We should be aware that this is based on just two individuals of race livingstoni, but given we have many more recordings of nominate, it seems likely that both races have indeed a somewhat different note in their song: livingstoni an irregular upslurred note, nominate an 'upside down sharp V'. If this is confirmed by more recordings, this can be considered a rather significant vocal difference. 


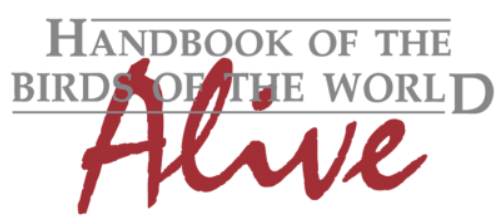

ORNITHOLOGICAL NOTES
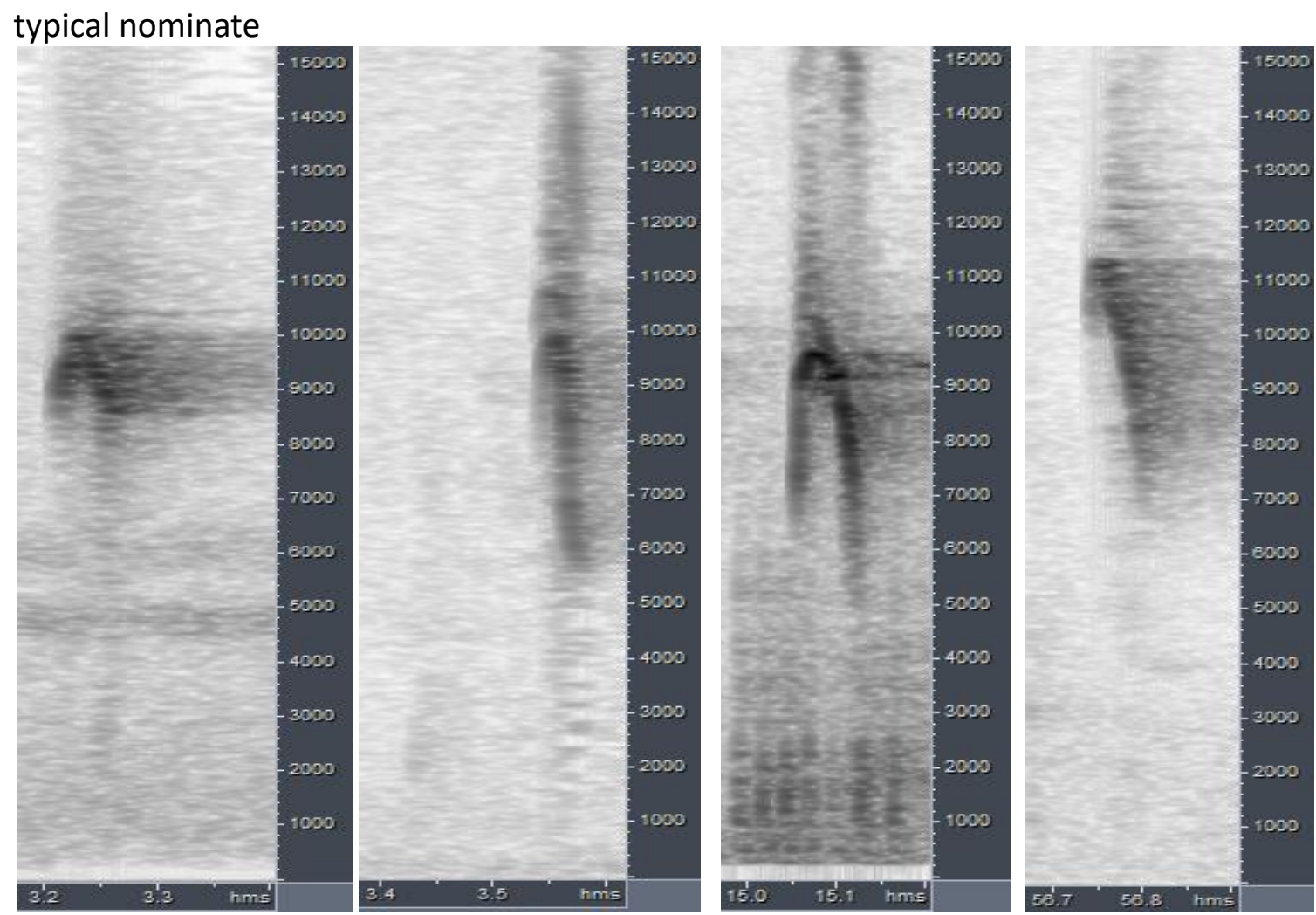

livingstoni

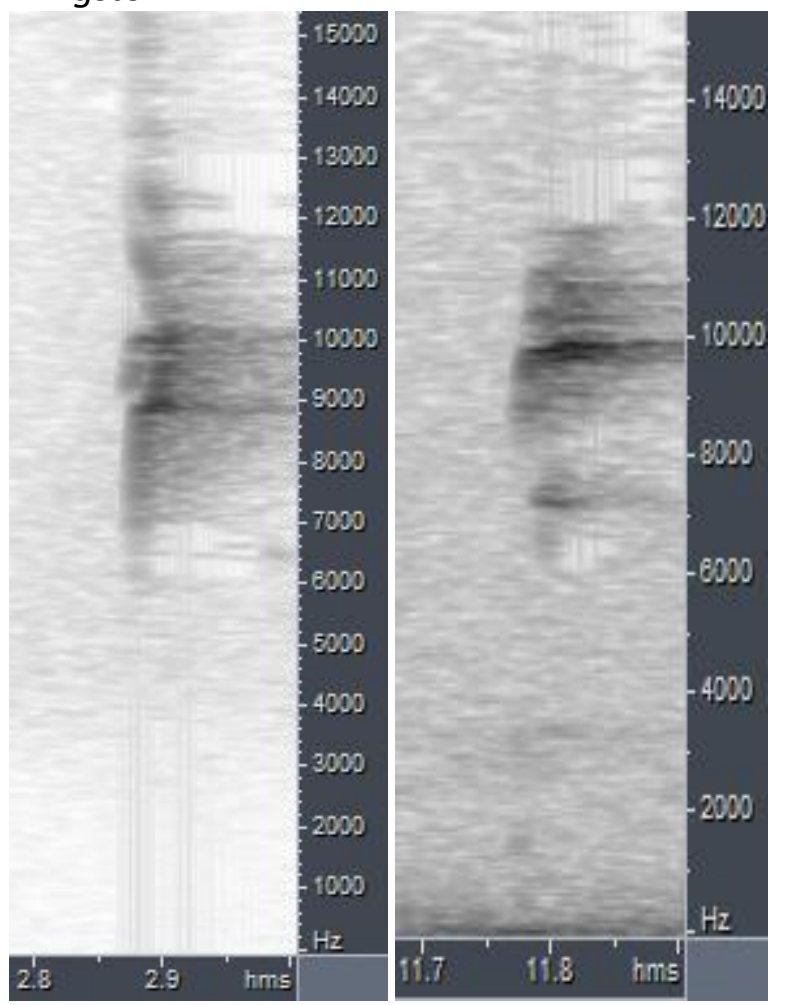


This note was finalized on 28th October 2016, using sound recordings available on-line at that moment. We would like to thank in particular the many sound recordists who placed their recordings for this species on XC, and Johnnier Arango-Bermúdez for the sole recordings of race livingstoni.

\section{References}

Tobias, J.A., Seddon, N., Spottiswoode, C.N., Pilgrim, J.D., Fishpool, L.D.C. \& Collar, N.J. (2010). Quantitative criteria for species delimitation. Ibis 152(4): 724-746.

\section{Recommended citation}

Boesman, P. (2016). Notes on the vocalizations of Dusky Bush-tanager (Chlorospingus semifuscus). HBW Alive Ornithological Note 445. In: Handbook of the Birds of the World Alive. Lynx Edicions, Barcelona. (retrieved from http://www.hbw.com/node/1287377 on 9 December 2016). 